\title{
Rheumatologist perspective of the Brazilian consensus for detection of auto antibodies in HEp-2 CELLS
}

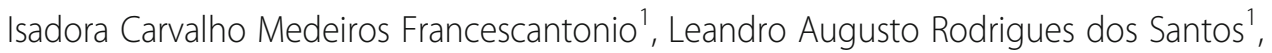
Paulo Luiz Carvalho Francescantonio ${ }^{1}$, Luiz Eduardo Coelho Andrade ${ }^{2}$ and Wilson de Melo Cruvinel ${ }^{1 *}$ (ID

\begin{abstract}
Objective: To evaluate the perception of rheumatologists regarding the recommendations of the Brazilian Consensus for detection of Autoantibodies (BCA) on HEp-2 Cells by Indirect Immunofluorescence assay (IFA) and how BCA recommendations help in clinical practice.

Methodology: A structured questionnaire regarding the BCA recommendations for detection and interpretations of autoantibodies in HEp-2 cells was applied to randomly selected rheumatologists. The results were tabulated using the Microsoft ${ }^{\oplus}$ Excel program, expressed as a simple percentage and the dichotomous data were analyzed using the Chi-square test and the Epi Info ${ }^{\oplus}$ program.

Results: Four hundred fuorteen rheumatologists participated in the study: $70 \%$ of them considered their knowledge of the HEp-2 IFA test satisfactory or excellent, and 43\% said they knew the BCA recommendations in general, without distinguishing the edition of the BCA to which they refer. The Revista Brasileira de Rheumatologia/ Advances in Rheumatology was the means of dissemination most consulted by specialists (50\%). According to the rheumatologists' opinion, the most relevant pattern was the homogeneous nuclear (78\%) and 65\% stated they were satisfied with the BCA recommendations at a level of satisfaction greater than or equal to $80 \%$. There was no significant difference in the perception of rheumatologists from the several Brazilian geographic regions.

Conclusion: Brazilian rheumatologists are aware of the BCA guidelines and most are satisfied with the content published, considering that the BCA recommendations assist positively in the clinical practice. Most rheumatologists recognize the patterns associated with rheumatic autoimmune diseases and have used BCA recommendations to interpret the results of the HEp-2 IFA test.
\end{abstract}

Keywords: Anti-nuclear antibodies, ANA, HEp-2, Autoimmunity

\section{Introduction}

The evaluation of autoantibodies by indirect immunofluorescence in HEp-2 cells (IFA HEp-2) represents, in the current context, a relevant tool for the diagnostic investigation of systemic autoimmune diseases in the scope of rheumatology, hepatology, pulmonology,

\footnotetext{
* Correspondence: melocruvinel@gmail.com

'Pontifícia Universidade Católica de Goiás (PUC Goiás), Escola de Ciências Médicas, Farmacêuticas e Biomédicas, Avenida Universitária 1.440, Setor Universitário, Goiânia, GO, Brazil

Full list of author information is available at the end of the article
}

dermatology, hematology, and other medical specialties [1]. In recent years, the test methodology has undergone an intense improvement and standardization process, especially regarding diagnostic performance and interpretation [2-6]. Such standardization procedures began in Brazil in 2000, in Goiania, with the first Brazilian Consensus for antinuclear antibodies detection on HEp-2 cells (BCA), serving as a reference for other international standardization initiatives, with emphasis for the International Consensus on ANA Patterns - ICAP [7-11].

(c) The Author(s). 2021 Open Access This article is licensed under a Creative Commons Attribution 4.0 International License, which permits use, sharing, adaptation, distribution and reproduction in any medium or format, as long as you give appropriate credit to the original author(s) and the source, provide a link to the Creative Commons licence, and indicate if changes were made. The images or other third party material in this article are included in the article's Creative Commons licence, unless indicated otherwise in a credit line to the material. If material is not included in the article's Creative Commons licence and your intended use is not permitted by statutory regulation or exceeds the permitted use, you will need to obtain permission directly from the copyright holder. To view a copy of this licence, visit http://creativecommons.org/licenses/by/4.0/. 
Five editions of the BCA and four international Workshops were published on the matter [2-11].

The first BCA was motivated by three main aspects: 1 ) heterogeneous nomenclature of the immunofluorescence patterns in Brazil since the same pattern had different denominations; 2) absence of parametric guidelines for reading the slides; and 3) lack of an algorithm for pattern organization into coherent classification groups [2].

The $\mathrm{BCA}$ organized the various patterns into coherent groups and stratified them in a classification tree [2]. The recognition, denomination, and classification of the patterns followed morphological criteria, i.e., the nomenclature and classification obeyed and reflected the distinctive morphological characteristics of each pattern. Besides, the first edition of the BCA encompassed the initial sample dilution approach for assay screening and indicated a systematic protocol for reading the slides [2].

Standardization recommendations were improved along successive BCA editions, encompassing new recommendations based on the doubts that arose by using the recommendations and classifications established in previous versions [3-6].

In 2014, during the 12th Workshop on Autoantibodies and Autoimmunity in São Paulo - Brazil, the First International Consensus on ANA Patterns (ICAP) was held [7]. With participation of European, North American, South American, and Asian specialists, this initiative adopted the Brazilian Consensus basic guidelines and defined a classification tree with three groups: nuclear, cytoplasmic, and mitotic [7]. In their first edition, the patterns received alphanumeric codes from AC-1 to AC-28 [7]. Some patterns discussed were not incorporated into the classification tree, reserved for subsequent discussions [7]. The first ICAP has already highlighted some clinical correlations of the patterns presented [7]. The international ICAP group produced four additional publications that, like BCA, have progressively improved the initial recommendations based on the practical application of the proposed algorithm, community feedback, and the acquisition of new scientific information [8-11].

In 2018, the fourth ICAP workshop, held in Germany during the 13th Dresden Autoantibody Symposium, recognized and incorporated the AC-0 pattern into the classification tree, defined as the pattern for a negative reaction; the $\mathrm{AC}-\mathrm{XX}$ pattern, used to report patterns not included in the tree; and the AC-29 pattern, corresponding to the characteristic compound pattern caused by anti-topoisomerase I antibodies $[9,11]$.

The V BCA, held in 2016 during the XXXIII Brazilian Congress of Rheumatology, had as main objective the harmonization between the algorithms of the Brazilian and International Consensus [6]. Thus, the V BCA incorporated the ICAP alphanumeric code system for the classification of BCA patterns. However, in some specific points, the original arrangement of $\mathrm{BCA}$ was maintained: 1) the recognition of 33 patterns was kept while ICAP recognizes 30 patterns; 2) nucleolar patterns were maintained as a distinct group; 3 ) the dichotomous classification of the speckled nuclear pattern was preserved in two subgroups, with positive metaphase plate and negative metaphase plate, respectively; 4 ) the centromere pattern linked to the group of speckled nuclear patterns was maintained; 5) the speckled pattern with isolated dots was maintained in the subgroup of the negative metaphase plate patterns; 6) the Mitotic chromosomal pattern (AC-28) was not incorporated; 7) the concept of compound patterns was maintained, encompassing the CENP-F and Topo I patterns, among the rest of the group of compound patterns [6]. Finally, the V BCA recommends the designation (ANA - anti-cell antibody test) for the assay, in Portuguese "FAN - Pesquisa de Anticorpos Anticélula" [6]. With respect to the name of the test, it is worth noting that the following VI BCA Workshop, during the 36th Brazilian Congress of Rheumatology, held in Fortaleza in 2019, decided to adhere to the ICAP recommendation, stating that the name of the test should emphasize the method (indirect immunofluorescence assay on HEp-2 cells - HEp-2 IFA). The designation HEp-2 IFA contemplates reactivity against the various cellular domains and not only to the nucleus, as is the case for antinuclear antibody test.

Based on the BCA pioneering spirit and the development of ICAP in recent years, there has been a continuous wide-ranging international discussion that has led to significant evolution and implementation of methodological and interpretative criteria. It included the recognition of more than 30 simple patterns, the inclusion of new patterns, several possibilities of compound patterns, as well as progressive encouragement to the implementation of standardized parameters of reading, interpretation, and quality control of the HEp-2 IFA test [2-5]. Faced with this continually changing reality, physicians who deal with the interpretation of HEp-2 IFA reports daily must be updated and able to interpret the results in all their magnitude and carry out a relevant clinical correlation for patients' benefit.

As a screening test for the presence of autoantibodies, there is no perfect association between the pattern and the specific autoantibody in the sample. For this reason, isolated HEp-2 IFA results do not allow definitive clinical conclusions. Concerning immunological associations, various patterns suggest certain autoantibodies; however, specific immunoassays must confirm these in any given sample. Thus, the potential benefit of HEp-2 IFA in the clinical practice depends on the attending physician's knowledge about its limitations, the significance of each immunofluorescence pattern, and the 
impact of the titer [12]. Its use in the clinical practice comes up against some obstacles, such as the historical paradigm that a positive HEp-2 IFA test necessarily implies autoimmune disease as well as the contrasts in the previous literature and $\mathrm{BCA} / \mathrm{ICAP}$ recommendations regarding pattern designation and correlations with autoantibodies and diseases [12].

Systemic Lupus Erythematosus (SLE), characterized by an extremely high frequency of positive HEp-2 IFA results, can elicit different patterns according to the type of underlying autoantibody [12]. However, a positive HEp-2 IFA result happens in several other diseases, up to $35 \%$ at the $1 / 40$ dilution [13] including asymptomatic individuals that show a positivity rate between 12 and $20 \%$ positivity at the $1 / 80$ dilution [14]. This positivity rate in apparently healthy individuals reflects possibly a certain degree of physiological autoimmunity. This tendency seems exacerbated in patients with nonautoimmune diseases, which present a higher frequency and titer of HEp-2 IFA than healthy individuals [13-15].

The unawareness of the limitation that a positive HEp2 IFA test may occur in non-autoimmune individuals could lead to an incorrect diagnosis of autoimmunity, generating exposure to unnecessary and potentially harmful treatment [12]. This scenario can be exacerbated because of the significant heterogeneity of methodological protocols and criteria for the exam interpretation. Therefore, to support the assistant physician's clinical reasoning, consistent standardization in the test methodology, interpretation, and reporting is essential $[7,16]$.

Regarding the clinical laboratory and the direct patient care, the consensus in HEp-2 IFA aim to offer such standardization guidelines to health professionals, aiming to ensure the best results for patients' treatment. It is up to the professional involved in dealing with this test to know the methodological and interpretation guidelines and to contribute to its improvement. Considering that BCA is completing two decades of existence, it is essential to investigate its penetration among the specialist most frequently interested in its use, that is, the rheumatologist. This study intended to evaluate rheumatologists' knowledge about BCA guidelines and how BCA recommendations help their clinical practice.

\section{Methodology}

This is a cross-sectional quantitative study, carried out using a structured questionnaire drawn up together with the Laboratory Committee of the Brazilian Society of Rheumatology (SBR). The work was approved by the research ethics committee of the Pontifícia Universidade Católica de Goiás (PUC Goiás), under the number 2872574 .
The virtual questionnaire development used HTML5, CSS3, JQuery, and PHP 5, in a MySQL database hosted on a server with Linux Operating System and Apache 2.2 web server. The structured questionnaire form was applied using a virtual platform at the official electronic address of the Brazilian Consensus as well as using a physical form during the 36th Brazilian Congress of Rheumatology in Fortaleza, Ceará (detailed below).

The SBR Laboratory Committee sent an e-mail to all rheumatologists enrolled in the SBR with an invitation to participate in the survey, with the respective link to access the form. The invitation link directed the participant to the official page of the Brazilian Consensus (http://www.hep-2.com.br), where the physician first accessed the informed consent form. After voluntary agreement, the participant was directed to the survey form. To avoid double responses by the same physician, participants provided their e-mail, and the platform restricted one response to each e-mail address. The questionnaire was available online to participants for the entire survey period, which was from January to December 2019 , so that during the entire survey period the participants could edit their responses. After confirming responses, the participant no longer had access to edit the submitted form. Participants that did not complete the form as well as non-rheumatologists were excluded from the survey.

In addition to the virtual platform, face-to-face data collection took place during the 36th Brazilian Congress of Rheumatology. With authorization from SBR, the congress participants were approached and invited to fill in the survey form, either online, as detailed in the previous paragraph, or using a physical questionnaire form to be posted on the digital platform. From these two platforms, we obtained responses from 521 participants. Participants that did not complete the form and those that did not refer to themselves as rheumatologists had their records dismissed and therefore 414 participants were eligible to compose the sample.

The data analysis used a simple percentage method from the Microsoft ${ }^{\circ}$ Excel 2016 program and the Chisquare test was used to dichotomous comparisons by geographic regions, after excluding the non-responders and non-rheumatologists, using the Epi Info ${ }^{\mathrm{Tw}}$ program. A threshold of 0.05 was defined for the establishment of statistical significance.

\section{Results}

The SBR database registers 2359 rheumatologists as members. Of these, $3.7 \%(87)$ are in the North region, $15.4 \%$ (363) in the Northeast, 7.8\% (185) in the Midwest, $57.6 \%$ (1559) in the Southeast, and $15.8 \%$ (365) in the South region of the country. The sample consisted of 414 participants, representing $17.5 \%$ of the SBR 
member-rheumatologists. This amount was considered satisfactory since a representative sample would correspond to 331 participants, with a $95 \%$ confidence interval, calculated by the software BioEstat 5.3.

As shown in Table 1, there were participants from all Brazilian regions, covering the 26 Brazilian states and the Federal District, with the largest number of participants from the Southeast followed by Northeast, South, Midwest, and North regions. Five participants (1.2\%) did not answer question regarding the Brazilian region.

Regarding the nature of the institutions where the rheumatologists worked (public and private), the group proved quite heterogeneous. Among the 414 participants, 44\% (184) work in institutions of the Brazilian Unified Health System, 7\% (29) in state public universities and $17 \%$ (70) in federal public universities, $72 \%$
(298) in private institutions, and 10\% (42) in private universities. One hundred and sixty-one (39.0\%) participants stated that they work simultaneously in public and private institutions. Of the total, 25 (6\%) participants did not answer this question.

One of the aspects evaluated was the selfperception of rheumatologists' knowledge about BCA guidelines. As detailed in Table 2, we observed a considerable variation in this parameter: $70 \%$ of the participants said they had satisfactory or excellent knowledge, $19 \%$ average knowledge, and $8 \%$ scarce or insufficient knowledge. Only 3\% of respondents did not answer this query. When we grouped the degree of knowledge attributed to the BCA into two categories, we verified no statistically significant difference between the country's five regions (Table 2).

Table 1 Distribution of rheumatologists and participants according to the state of the federation

\begin{tabular}{|c|c|c|c|}
\hline Region & State & Number of rheumatologists & Number of study participants \\
\hline \multirow[t]{7}{*}{ North 18 (4\%) } & Acre & $5(0.2 \%)^{\mathrm{a}}$ & $1(20 \%)^{b}$ \\
\hline & Amazonas & $17(1 \%)$ & $5(29 \%)$ \\
\hline & Amapá & $5(0.2 \%)$ & $1(20 \%)$ \\
\hline & Pará & $30(1 \%)$ & $6(20 \%)$ \\
\hline & Rondônia & $11(1 \%)$ & $2(18 \%)$ \\
\hline & Roraima & $2(0.1 \%)$ & $1(50 \%)$ \\
\hline & Tocantins & $13(1 \%)$ & $2(15 \%)$ \\
\hline \multirow[t]{9}{*}{ Northeast 72 (17\%) } & Alagoas & $27(3 \%)$ & $4(15 \%)$ \\
\hline & Bahia & $65(3 \%)$ & $10(15 \%)$ \\
\hline & Ceará & $75(3 \%)$ & $16(21 \%)$ \\
\hline & Maranhão & $13(1 \%)$ & $6(46 \%)$ \\
\hline & Paraíba & $38(2 \%)$ & $3(8 \%)$ \\
\hline & Pernambuco & $47(2 \%)$ & $16(34)$ \\
\hline & Piauí & $24(1 \%)$ & $6(25 \%)$ \\
\hline & Rio Grande do Norte & $34(2 \%)$ & $8(24 \%)$ \\
\hline & Sergipe & $18(1 \%)$ & $3(17 \%)$ \\
\hline \multirow[t]{4}{*}{ Midwest 37 (9\%) } & Federal District & $105(5 \%)$ & $13(12 \%)$ \\
\hline & Goiás & $56(3 \%)$ & $16(29 \%)$ \\
\hline & Mato Grosso & $26(1 \%)$ & $2(8 \%)$ \\
\hline & Mato Grosso do Sul & $45(2 \%)$ & $6(13 \%)$ \\
\hline \multirow[t]{4}{*}{ Southeast 230 (56\%) } & Espírito Santo & $71(3 \%)$ & 7 (10\%) \\
\hline & Minas Gerais & $260(12 \%)$ & $50(19 \%)$ \\
\hline & Rio de Janeiro & $163(8 \%)$ & $42(26 \%)$ \\
\hline & São Paulo & $563(26 \%)$ & $131(23 \%)$ \\
\hline \multirow[t]{4}{*}{ South 52 (13\%) } & Paraná & 179 (8\%) & $29(16 \%)$ \\
\hline & Rio Grande do Sul & $167(8 \%)$ & $8(5 \%)$ \\
\hline & Santa Catarina & $91(4 \%)$ & 15 (16\%) \\
\hline & BRAZIL & $2150(100 \%)^{c}$ & 409 (19\%) \\
\hline
\end{tabular}

${ }^{a}$ Percentage concerning the total number of rheumatologists in the country; ${ }^{b}$ Percentage concerning the total number of rheumatologists in the respective State; ${ }^{c}$ Total rheumatologists in Brazil, data obtained from the federal council of medicine 
Table 2 Rheumatologists' self-assessment regarding knowledge about the Brazilian Consensus on antinuclear antibodies

\begin{tabular}{|c|c|c|c|c|c|c|c|}
\hline Region & $\mathrm{N}$ & NE & $\mathrm{CO}$ & $\mathrm{S}$ & SE & SR & Total \\
\hline Total Participants & $18(4 \%)^{a}$ & $72(17 \%)$ & $37(9 \%)$ & $52(13 \%)$ & $230(56 \%)$ & $5(1 \%)$ & $414(100 \%)$ \\
\hline \multicolumn{8}{|c|}{ Knowledge about the Brazilian Consensus in IFA-HEp 2: } \\
\hline Satisfactory & $14(78 \%)^{b}$ & $38(53 \%)$ & $20(54 \%)$ & $29(56 \%)$ & $138(60 \%)$ & $2(40 \%)$ & $241(58 \%)$ \\
\hline Limited & $2(11 \%)$ & $4(6 \%)$ & $2(5 \%)$ & $3(6 \%)$ & $9(4 \%)$ & $1(20 \%)$ & $21(5 \%)$ \\
\hline Reasonable & $1(5,5 \%)$ & $19(26 \%)$ & $8(22 \%)$ & $14(27 \%)$ & $37(16 \%)$ & $1(20 \%)$ & $80(19 \%)$ \\
\hline Excellent & $1(5,5 \%)$ & $10(14 \%)$ & $3(8 \%)$ & $4(8 \%)$ & $30(13 \%)$ & $1(20 \%)$ & 49 (12\%) \\
\hline Insufficient & $0(0 \%)$ & $0(0 \%)$ & $1(3 \%)$ & $2(4 \%)$ & $8(3 \%)$ & $0(0 \%)$ & $11(3 \%)$ \\
\hline I don't know yet & $0(0 \%)$ & $0(0 \%)$ & $0(0 \%)$ & $0(0 \%)$ & $1(0 \%)$ & $0(0 \%)$ & $1(0 \%)$ \\
\hline Did not answer & $0(0 \%)$ & $1(1 \%)$ & $3(8 \%)$ & $0(0 \%)$ & $7(3 \%)$ & $0(0 \%)$ & $11(3 \%)$ \\
\hline Satisfactory/Excellent & $15(83 \%)$ & $48(68 \%)$ & $23(68 \%)$ & $33(63 \%)$ & $168(75 \%)$ & $3(60 \%)$ & $290(72 \%)^{c}$ \\
\hline Medium/Little/Insufficient & $3(17 \%)$ & $23(32 \%)$ & $11(30 \%)$ & 19 (58\%) & $54(23 \%)$ & $2(40 \%)$ & $113(27 \%)^{c}$ \\
\hline
\end{tabular}

a Percentage in relation to the total number of participants; ${ }^{\mathrm{b}}$ Percentage of total participants in the region; ${ }^{\mathrm{c}}$ Percentage in relation to the total of respondents in each region. Chi-square test: $p=0.237$

The knowledge of each edition of the BCA by the participants showed an increase over the successive editions: $16 \%$ (65) of the participants said they knew the first BCA, 14\% (60) the second BCA, 28\% (114) the third BCA, 36\% (151) the fourth BCA and 37\% (155) the fifth $\mathrm{BCA}$, with $43 \%$ (180) saying that they know the recommendations in general without distinguishing the edition of the BCA which they refer to. Only 2\% (10) said they were unaware of the Brazilian Consensus and 3\% (13) of the participants did not answer this query.

Concerning the first access to the BCA material, 50\% (205) of the participants were introduced to the BCA by the Brazilian Journal of Rheumatology, currently Advances in Rheumatology, 1\% (6) by the Brazilian Journal of Clinical Pathology and Laboratory Medicine, 28\% (114) in conferences at congresses, 30\% (125) by Internet search, $5 \%$ (17) by communications from scientific societies and 14\% (60) by the official BCA website (www. hep-2.com.br). A total of 4\% (18) did not inform the source of information for BCA access, and 5\% (19) did not answer this query. It is worth noting that the form allowed indicating more than one possibility; therefore, several participants informed more than one source for learning about BCA.

The frequency of HEp-2 IFA tests requested by the participants averaged 10.7 tests per week, with little significant variation among the five regions of the country (Table 3).

When asked about the use of BCA recommendations to support clinical correlations, $86 \%$ (354) of the participants stated that they use the recommendations daily, while $10 \%$ (44) said they do not use them at all, and $4 \%$ (16) of the participants did not answer this query (Table 4). The analysis using the $5 \times 2$ chi-square test, comparing the country's macro-regions, did not show any statistically significant difference for this parameter.

Regarding BCA's contributions to the HEp-2 IFA report, $76 \%$ (315) of the participants consider that the process of nomenclature standardization has made their understanding clearer, while 7\% (29) think otherwise. In this assessment, $17 \%$ (70) did not answer this query (Table 4). The analysis using the chi-square test showed that there was no statistically significant difference among the five macro-regions of the country.

Assessing the influence of $\mathrm{BCA}$ on clinical correlations, $78 \%$ of participants (321) believe that BCA has made clinical correlations clearer, while 5\% (17) think otherwise and $17 \%$ (72) of participants have not responded to this question (Table 4). Again, the analysis using the chi-square test showed that no statistically significant difference among the five macro-regions of the country.

Table 3 Frequency of HEp-2 IFA tests requested per week by rheumatologists in the five Brazilian macro-regions

\begin{tabular}{llllllll}
\hline Geographic region & $\mathbf{N}$ & NE & CO & S & SE & NS & Total \\
\hline $\begin{array}{l}\text { Number of rheumatologists } \\
\text { Average (standard deviation) }\end{array}$ & 18 IFA-HEp2 exams & ordered per week & & $52(13 \%)$ & $230(56 \%)$ & $5(1 \%)$ & $414(100 \%)$ \\
Average & $\mathbf{9 . 5} \pm \mathbf{8 . 9 6}$ & $\mathbf{1 1 . 8 \pm 1 4 . 8 3}$ & $\mathbf{1 2 . 5 \pm 1 1 . 0 4}$ & $\mathbf{8 . 3 \pm 6 . 4 5}$ & $\mathbf{1 1 . 0 \pm 9 . 8 5}$ & $\mathbf{1 0 . 7 \pm 1 0 . 6 9}$ \\
No answer & 2 & 2 & 7 & 3 & 20 & 1 & 35 \\
\hline
\end{tabular}

N North, NE Northeast; CO Midwest; S South; SE Southeast, NS Not specified 
Table 4 Rheumatologist's perception of the role of the Brazilian Consensus in clinical practice

\begin{tabular}{|c|c|c|c|c|c|c|c|}
\hline Geographic Macro-Region & $\mathbf{N}$ & NE & $\mathrm{CO}$ & S & SE & SR & Total \\
\hline Number of rheumatologists & $18(4 \%)$ & $72(17 \%)$ & $37(9 \%)$ & $52(13 \%)$ & $230(56 \%)$ & $5(1 \%)$ & $414(100 \%)$ \\
\hline \multicolumn{8}{|c|}{ Do you rely on BCA recommendations to support clinical correlations? * } \\
\hline Yes & $13(72 \%)$ & $64(89 \%)$ & $33(89 \%)$ & $46(88 \%)$ & $193(84 \%)$ & $5(100 \%)$ & $354(86 \%)$ \\
\hline No & $3(17 \%)$ & $6(8 \%)$ & $1(3 \%)$ & $5(10 \%)$ & $29(13 \%)$ & $0(0 \%)$ & $44(10 \%)$ \\
\hline Did not answer & $2(11 \%)$ & $2(3 \%)$ & $3(8 \%)$ & $1(2 \%)$ & $8(3 \%)$ & $0(0 \%)$ & $16(4 \%)$ \\
\hline \multicolumn{8}{|c|}{ Did BCA make the understanding of the report clearer? ** } \\
\hline Yes & $15(83 \%)$ & $60(83 \%)$ & $29(78 \%)$ & $40(77 \%)$ & $168(73 \%)$ & $3(60 \%)$ & $315(76 \%)$ \\
\hline No & $1(6 \%)$ & $2(3 \%)$ & $1(3 \%)$ & $4(8 \%)$ & $19(8 \%)$ & $2(40 \%)$ & $29(7 \%)$ \\
\hline Did not answer & $2(11 \%)$ & $10(14 \%)$ & $7(19 \%)$ & $8(15 \%)$ & $43(19 \%)$ & $0(0 \%)$ & $70(17 \%)$ \\
\hline \multicolumn{8}{|c|}{ Has the Consensus made clinical correlations clearer? $* * *$} \\
\hline Yes & $14(78 \%)$ & $61(85 \%)$ & $28(76 \%)$ & $43(83 \%)$ & $172(75 \%)$ & $3(60 \%)$ & $321(78 \%)$ \\
\hline No & $1(5 \%)$ & $2(3 \%)$ & $2(5 \%)$ & $0(0 \%)$ & $14(6 \%)$ & $2(40 \%)$ & $21(5 \%)$ \\
\hline Did not answer & $3(17 \%)$ & $9(12 \%)$ & 7 (19\%) & $9(17 \%)$ & 44 (19\%) & $0(0 \%)$ & $72(17 \%)$ \\
\hline
\end{tabular}

$N$ North, NO Northeast; CO Midwest; S South; SE Southeast, SR No region.

Chi-square test: ${ }^{*} p=0.329,{ }^{* *} p=0.386,{ }^{* * *} p=0.59$

When asked about the information that should be present in the HEp-2 IFA report, 76\% (316) indicated the identification of the pattern name, 25\% (103) supported the inclusion of the international alphanumeric code of the pattern (AC code from ICAP), 63\% (261) the final title, $47 \%$ (194) the cell compartment that appears fluorescent, $32 \%$ (134) the information about the chromosomal metaphase plate, 38\% (158) the note with the pattern clinical relevance, and $35 \%$ (144) the HEp-2 IFA patterns in previous exams, with $19 \%$ (79) of the participants not answering this query. It is worth noting that the form allowed indicating more than one possibility; therefore, several participants informed more than one item to be included in the report.

Table 5 details the participants' perception of the importance of different nuclear patterns. Most rheumatologists demonstrated intimacy with the various nuclear patterns, and the perceived relevance varied among patterns. The most recognized nuclear patterns were the homogeneous (AC-1), coarse speckled (AC-5), and centromere (AC-3). The fine speckled nuclear pattern (AC-4) was considered relevant by just over half of the participants, while the dense fine speckled (AC-2) and reticular coarse speckled (BAC-4) patterns were considered pertinent by about $1 / 3$ of the participants. The other nuclear patterns were considered relevant by only a small portion of the participants. One percent said they were unfamiliar with these patterns, and $0.5 \%$ did not consider these types of pattern to be necessary.

Regarding the nucleolar group, still in Table 5, these patterns were also recognized by most of the participants. The most acknowledged patterns were the homogeneous (AC-8) and the punctate (AC-10). Only 9\% of participants did not confirm familiarity with this group of patterns, and $1 \%$ did not consider them essential.

When asked about the importance of the cytoplasmic pattern group, the most acknowledged was the fine speckled (AC-20) and the reticular speckled (AC-21). In general, the interviewees were less familiar with the cytoplasmic group of patterns, but only $16 \%$ said they did not know any the of the cytoplasmic patterns (Table 5).

Regarding the mitotic group patterns, the most acknowledged were the mitotic spindle fibers and the Spindle fibers NuMA-2 (AC-25). Also the mitotic group of patterns was unknown for many of the participants, with $26 \%$ saying they did not know them at all. In the histograms presented in Fig. 1, it is possible to verify in global terms the percentage of relevance attributed by rheumatologists to each group of patterns: nuclear, nucleolar, cytoplasmic, and mitotic.

Figure 2 shows the degree of satisfaction of the participants regarding the contributions of the Consensus (Brazilian and International) to clinical practice, graded on a scale from 0 to 10 . The BCA was rated as $\geq 7.0$ by $74 \%$ of the participants, as $\geq 8.0$ by $65 \%$, and as $\geq 9.0$ by $41 \%$ of the participants.

When asked about the awareness on the International Consensus (ICAP), 50\% (208) of the participants said they know it, and 30\% (123) said they do not know it, and $20 \%$ (83) of the participants did not answer this query. In relation to the assessment of ICAP's contribution to the clinical practice, on a scale of 0 to 10 regarding the participant's satisfaction with the contributions of ICAP to clinical practice, $50 \%$ assigned a score $\geq 7.0$, and $22.5 \%$ a score $\leq 6.0$. 
Table 5 Distribution of nuclear, nucleolar, cytoplasmic and mitotic apparatus patterns according to the relevance perceived by rheumatologists in different Brazilian macro-regions

\begin{tabular}{|c|c|c|c|c|c|c|c|}
\hline Macro-region & $\mathrm{N}$ & NE & $\mathrm{CO}$ & $\mathrm{s}$ & SE & SR & Total \\
\hline Total & $18(4 \%)$ & $72(17 \%)$ & $37(9 \%)$ & $52(13 \%)$ & $230(56 \%)$ & $5(1 \%)$ & $414(100 \%)$ \\
\hline \multicolumn{8}{|l|}{ Nuclear patterns } \\
\hline Reticular coarse & $28 \%{ }^{\mathrm{a}}$ & $28 \%$ & $24 \%$ & $40 \%$ & $34 \%$ & $20 \%$ & $32 \%$ \\
\hline Quasi-homogeneous & $17 \%$ & $29 \%$ & $35 \%$ & $33 \%$ & $17 \%$ & $20 \%$ & $23 \%$ \\
\hline Homogenous & $78 \%$ & $83 \%$ & $78 \%$ & $71 \%$ & $79 \%$ & $40 \%$ & $78 \%$ \\
\hline Dense fine speckled & $39 \%$ & $33 \%$ & $35 \%$ & $23 \%$ & $30 \%$ & $60 \%$ & $31 \%$ \\
\hline Centromere & $44 \%$ & $63 \%$ & $59 \%$ & $75 \%$ & $67 \%$ & $20 \%$ & $65 \%$ \\
\hline Fine speckled & $56 \%$ & $56 \%$ & $49 \%$ & $58 \%$ & $56 \%$ & $40 \%$ & $55 \%$ \\
\hline Large/coarse speckled & $83 \%$ & $82 \%$ & $62 \%$ & $75 \%$ & $71 \%$ & $40 \%$ & $73 \%$ \\
\hline Multiple nuclear dots & $6 \%$ & $8 \%$ & $14 \%$ & $10 \%$ & $5 \%$ & $0 \%$ & $7 \%$ \\
\hline Smooth/Punctate nuclear envelope & $11 \%$ & $8 \%$ & $8 \%$ & $13 \%$ & $11 \%$ & $0 \%$ & $10 \%$ \\
\hline Pleomorfic/PCNA & $6 \%$ & $14 \%$ & $11 \%$ & $13 \%$ & $16 \%$ & $0 \%$ & $14 \%$ \\
\hline Not familiar with the patterns & $0 \%$ & $0 \%$ & $0 \%$ & $0 \%$ & $1 \%$ & $0 \%$ & $1 \%$ \\
\hline Considers the patterns unimportant & $0,5 \%$ & $1 \%$ & $0 \%$ & $0 \%$ & $0 \%$ & $0 \%$ & $0 \%$ \\
\hline Did not answer & $11 \%$ & $7 \%$ & $19 \%$ & $13 \%$ & $14 \%$ & $40 \%$ & $13 \%$ \\
\hline \multicolumn{8}{|l|}{ Nucleolar patterns } \\
\hline Homogeneous nucleolar & $67 \%$ & $58 \%$ & $70 \%$ & $67 \%$ & $61 \%$ & $40 \%$ & $62 \%$ \\
\hline Clumpy nucleolar & $11 \%$ & $13 \%$ & $24 \%$ & $19 \%$ & $22 \%$ & $40 \%$ & $20 \%$ \\
\hline Punctate nucleolar & $44 \%$ & $43 \%$ & $49 \%$ & $40 \%$ & $43 \%$ & $60 \%$ & $44 \%$ \\
\hline Not familiar & $6 \%$ & $8 \%$ & $5 \%$ & $8 \%$ & $10 \%$ & $0 \%$ & $9 \%$ \\
\hline Unimportant & $0 \%$ & $4 \%$ & $0 \%$ & $0 \%$ & $0 \%$ & $0 \%$ & $1 \%$ \\
\hline Did not answer & $17 \%$ & $11 \%$ & $19 \%$ & $15 \%$ & $15 \%$ & $40 \%$ & $15 \%$ \\
\hline \multicolumn{8}{|l|}{ Cytoplasmic patterns } \\
\hline Fibrillar linear & $17 \%$ & $14 \%$ & $8 \%$ & $21 \%$ & $14 \%$ & $0 \%$ & $14 \%$ \\
\hline Fibrillar filamentous & $6 \%$ & $11 \%$ & $14 \%$ & $19 \%$ & $9 \%$ & $0 \%$ & $11 \%$ \\
\hline Fibrillar segmental & $6 \%$ & $8 \%$ & $5 \%$ & $13 \%$ & $10 \%$ & $0 \%$ & $9 \%$ \\
\hline Discrete dots & $17 \%$ & $14 \%$ & $19 \%$ & $19 \%$ & $18 \%$ & $0 \%$ & $17 \%$ \\
\hline Dense fine speckled & $22 \%$ & $32 \%$ & $30 \%$ & $21 \%$ & $29 \%$ & $20 \%$ & $28 \%$ \\
\hline Fine speckled & $17 \%$ & $33 \%$ & $35 \%$ & $27 \%$ & $42 \%$ & $20 \%$ & $36 \%$ \\
\hline Reticular/AMA & $22 \%$ & $33 \%$ & $35 \%$ & $40 \%$ & $30 \%$ & $60 \%$ & $33 \%$ \\
\hline Polar speckled & $6 \%$ & $14 \%$ & $14 \%$ & $17 \%$ & $9 \%$ & $20 \%$ & $11 \%$ \\
\hline Rods and rings & $6 \%$ & $28 \%$ & $22 \%$ & $19 \%$ & $13 \%$ & $0 \%$ & $17 \%$ \\
\hline Not familiar with the patterns & $6 \%$ & $13 \%$ & $11 \%$ & $17 \%$ & $18 \%$ & $0 \%$ & $16 \%$ \\
\hline Considers unimportant the patterns & $11 \%$ & $57 \%$ & $0 \%$ & $2 \%$ & $0 \%$ & $0 \%$ & $2 \%$ \\
\hline Did not answer & $17 \%$ & $13 \%$ & $19 \%$ & $15 \%$ & $17 \%$ & $40 \%$ & $17 \%$ \\
\hline \multicolumn{8}{|l|}{ Mitotic patterns } \\
\hline Spindle fibers & $0 \%$ & $24 \%$ & $32 \%$ & $19 \%$ & $38 \%$ & $40 \%$ & $31 \%$ \\
\hline Centrosome & $11 \%$ & $19 \%$ & $24 \%$ & $25 \%$ & $18 \%$ & $20 \%$ & $19 \%$ \\
\hline Spidle fibers NuMA ॥ & $28 \%$ & $32 \%$ & $27 \%$ & $40 \%$ & $31 \%$ & $0 \%$ & $32 \%$ \\
\hline Intercellular bridge & $6 \%$ & $21 \%$ & $8 \%$ & $17 \%$ & $11 \%$ & $20 \%$ & $13 \%$ \\
\hline Not familiar with the patterns & $33 \%$ & $31 \%$ & $14 \%$ & $29 \%$ & $26 \%$ & $20 \%$ & $26 \%$ \\
\hline Considers unimportant the patterns & $6 \%$ & $13 \%$ & $0 \%$ & $2 \%$ & $0 \%$ & $0 \%$ & $3 \%$ \\
\hline Did not answer & $22 \%$ & $14 \%$ & $22 \%$ & $17 \%$ & $19 \%$ & $40 \%$ & $18 \%$ \\
\hline
\end{tabular}

${ }^{a}$ Frequency of participants who consider the pattern relevant (in brackets the percentage relative to the total number of participants who answered this question in the respective region of the country)

$N$ North, NE Northeast; CO Midwest; S South; SE Southeast, SR No region 


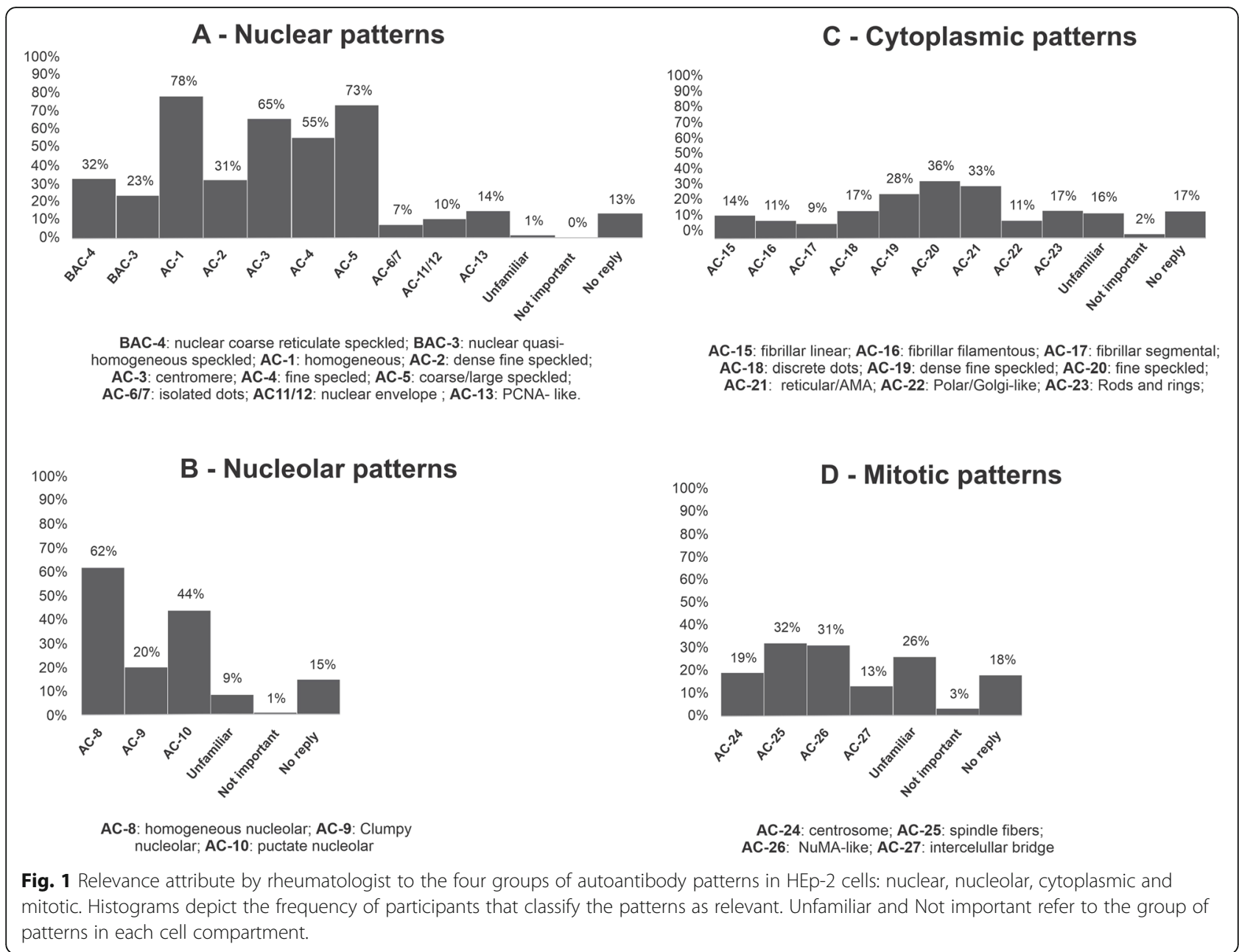

\section{Discussion}

The present study analyzed Brazilian rheumatologists' opinions about BCA's recommendations, the first evaluation of medical opinion 20 years after the first BCA Workshop [2]. Of the 414 participants included in the study, all are self-reported rheumatologists. The group contained representatives from the 26 Brazilian States and the Federal District, and these specialists operate in 127 Brazilian cities.

Systemic Autoimmune Rheumatic Diseases (SARD), a major object of study by the rheumatologist, consist of a group of diseases whose investigation may include the identification of autoantibodies, which function as diagnostic markers [12, 17]. These autoantibodies can be screened by the indirect immunofluorescence assay in HEp-2 cells, being expressed as immunofluorescence patterns [12]. Autoantibodies are part of the classification criteria of several SARD. In SLE, for example, the HEp-2 IFA test is positive in 95 to $100 \%$ of patients; in Systemic Sclerosis, in 60-80\%; in Sjögren's Syndrome, in 40-70\%; in Dermatomyositis, in $30-80 \%$ [18]. When a 1 : 80 serum dilution is considered in healthy individuals, there is a $10-13 \%$ positivity of the test $[14,18]$. Thus, the test alone does not determine any diagnosis [18]. It is just one of the classification criteria that can also be used in the list of diagnostic elements [19].

Among the limitations of the test are the fact that healthy individuals may have a positive test; diseases can be associated with different HEp-2 IFA patterns; variation between patterns may depend on variations in the test substrate $[12,14]$. Thus, the clinical relevance depends on the close correlation between the clinical context and the HEp-2 IFA pattern, both of which will to guide the next step, i.e., for the determination of diseaseassociated autoantibodies [12, 18].

Most of the participants in this study, 70\% (290), considered their knowledge regarding the HEp-2 IFA test to be satisfactory or excellent. In comparison, 27\% (112) considered it unsatisfactory. This percentage of $27 \%$ is considered high since the test is a diagnostic tool for frequent diseases in this specialist's clinical practice. Therefore, it is necessary to reinforce BCA's educational actions through continuing education projects in partnership with the Brazilian Society of Rheumatology. The 


\section{Degree of satisfaction regarding the Brazilian Consensus and the ICAP}

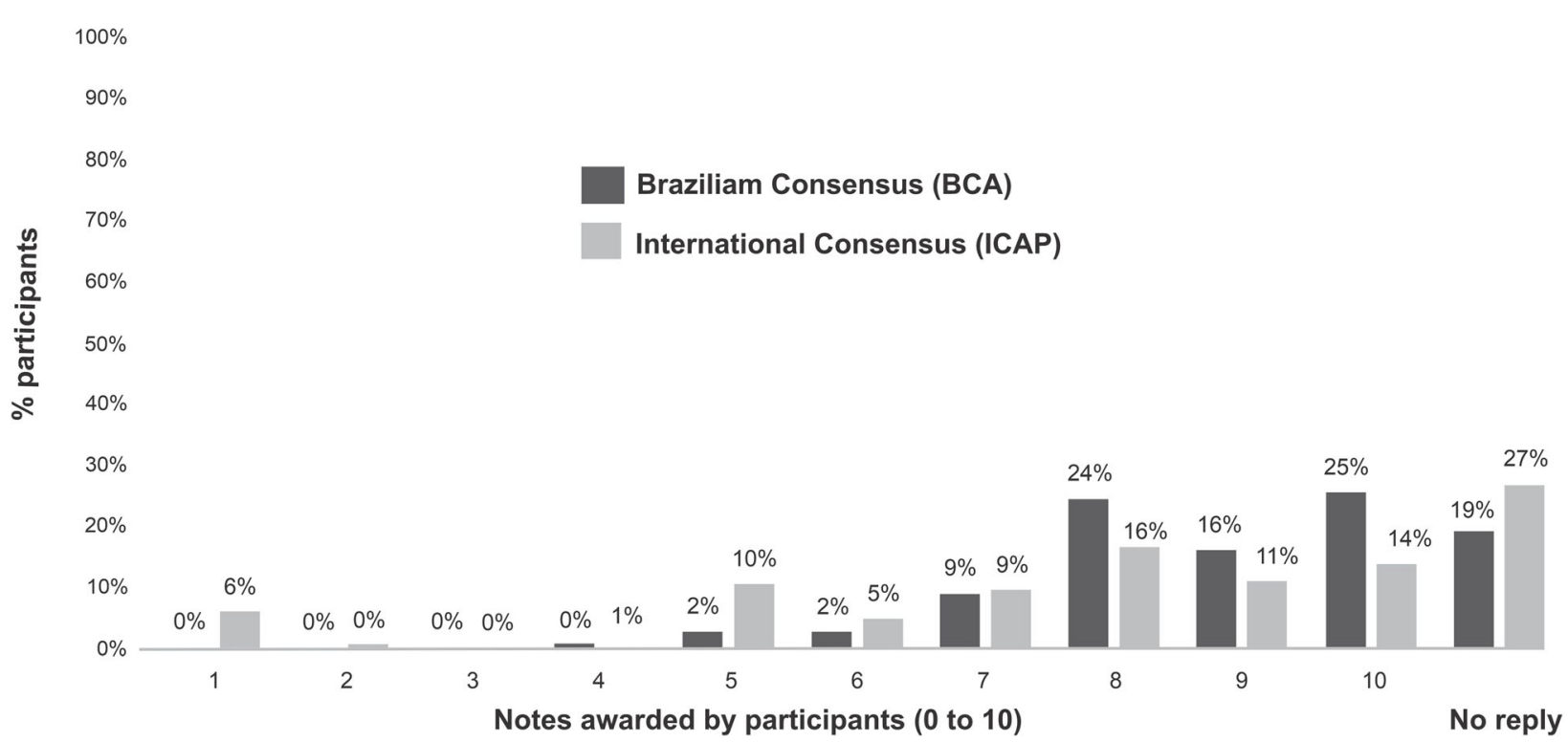

Fig. 2 Degree of satisfaction attribute of rheumatologist regarding the contributions of the Brazilian Consensus and the ICAP to clinical practice,

use of the HEp-2 IFA test in clinical practice is an important diagnostic tool and can only reach its full potential if there is complete knowledge of the specialists on how to interpret the test report. When this does not occur, the chance of misdiagnosis increases, and healthy individuals may be considered sick and vice versa. In addition, the correct ordering of reflex disease-specific antibodies is strongly helped by the knowledge of the relevance of HEp-2 IFA patterns [18].

The BCA was created to help the access to information about the HEp-2 IFA test and to systematize the interpretation of patterns regarding applicability in clinical practice. In addition, the standardized $\mathrm{BCA}$ nomenclature allows the reports to be reliable, reproducible, and suitable for long-term comparison [6-10]. The BCA information has been disseminated for about 20 years, and, in a way, it has been helping and guiding the rheumatologists' clinical practice when it comes to the HEp-2 IFA test interpretation. This action has been successful since only $2 \%$ of the study participants reported not knowing BCA.

About the use of $\mathrm{BCA}$ recommendations in clinical practice, $86 \%$ (354) of the participants stated that they use these guidelines to facilitate clinical correlations, $76 \%$ (315) consider that the proposed nomenclature standardization process made the understanding of the reports clearer, and 78\% (321) believe that BCA has made the clinical correlations as explicit as possible. Also, $65 \%$ of the participants said that their satisfaction with the $\mathrm{BCA}$ information is greater than or equal to $80 \%$. Therefore, we conclude that the BCA information has been useful for those who use such information in their routine operation.

Regarding the ways of getting to know the BCA material, $50 \%$ of the participants had access to the BCA by the journal Advances in Rheumatology, previously Brazilian Journal of Rheumatology, while only $14 \%$ actively sought an update through the BCA web page (http://www. hep-2.com.br/). Such data reinforces the need for joint work among the BCA team, rheumatologists, the SBR Laboratory Commission, and the Brazilian Society of Rheumatology, aiming to disseminate information and expand access.

When asked about the importance of several patterns, the participants considered the homogeneous nuclear pattern (AC-1) as the most important (78\%). Such information is consistent because this pattern is present almost exclusively in individuals with autoimmune diseases, especially in SLE [12, 20]. This pattern is related to anti-native DNA antibodies, which occur in $50-80 \%$ of individuals with SLE and is used to monitor disease activity. It is also related to the anti-nucleosome antibody, also a specific marker for SLE. Finally, the AC-1 pattern is associated with the anti-histone antibody, which is also frequently related to SLE and in druginduced SLE $[4,12,15]$.

Another pattern also pointed out as relevant was the nuclear centromere/AC-3 (65\%), strongly associated to 
systemic sclerosis and, as such, included in the classification criteria for this disease [12]. Its positivity in individuals with this diagnosis is around 70\% [18].

The coarse speckled nuclear pattern (AC-5) was also considered relevant by $73 \%$ of the participants. It can be found in individuals with SLE, systemic sclerosis, undifferentiated connective tissue disease, systemic sclerosis overlap syndrome - autoimmune myopathy, and mixed connective tissue disease [12, 20]. Its frequency varies among these autoimmune diseases, being virtually $100 \%$ in mixed connective tissue disease [20].

The fine speckled nuclear pattern (AC-4) was deemed essential by $55 \%$ of the participants and it is associated with the presence of anti-SS-B/La and anti-SS-A/Ro autoantibodies, found in Sjögren's syndrome, SLE, cutaneous lupus erythematosus, neonatal lupus, rheumatoid arthritis, myositis associated with systemic sclerosis, and polymyositis [12, 20]. Its frequency in individuals with these disease varies from 15 to $65 \%[20]$.

Among the participants, $62 \%$ of them find the homogeneous nucleolar pattern (AC-8) important. It is associated with anti-PM/Scl antibody when it is accompanied by a nuclear fine speckled pattern, being observed mainly in the association of systemic sclerosis and inflammatory myopathy $[12,20]$. Other thant that, the AC-8 pattern may indicate the rare anti-To/ Th antibodies. Interestingly, a low number of rheumatologists attributed importance to the clumpy nucleolar pattern (AC-9). However, this pattern is associated with the anti-fibrillarin antibody, a specific marker of systemic sclerosis. Considering the high number of rheumatologists who attributed importance to homogeneous nucleolar patterns (62\%) and nucleolar speckled patterns (40 to 60\%), many can speculate that several rheumatologists were mistaken when answering the questionnaire, taking the nucleolar patterns by nuclear patterns. This possible mistake could explain the high degree of importance given to the homogeneous nucleolar pattern, since the homogeneous nuclear pattern (AC-1) has justified importance. However, this is a speculative possibility that would need further investigation.

In general, the patterns best known by rheumatologists are related to recurrent diseases in the clinical practice and the same disease can be associated with different patterns $[10,20]$. With this perspective, the relevance attributed by rheumatologists to the four groups of autoantibody patterns was greater for the nuclear and nucleolar patterns, followed by cytoplasmic and mitotic.

It is noteworthy that some patterns with no established clinical correlation were also considered important by a large number of specialists. As examples, we have the quasi-homogeneous speckled nuclear pattern (BAC-3) that was considered necessary by $23 \%$ of the participants; and the nuclear reticular coarse speckled (BAC-4), which was deemed important by $32 \%$ of the participants. In contrast, the dense fine speckled cytoplasmic pattern (AC-19), associated with the presence of anti-P-ribosomal protein antibody in SLE, was considered relevant. Other clinically relevant patterns that were not highly rated by the participants were the fine speckled cytoplasmic pattern (AC-20) (36\%), associated with anti-Jo1 antibody in polymyositis, and the reticular cytoplasmic pattern (AC-21) (33\%), associated with the presence of anti-mitochondria antibody in Primary Biliary Cholangitis [12].

Due to the design of the questionnaire, the study does not allow us to conclude on the reasons why rheumatologists attributed importance to some patterns. Possible criteria would include the clinical correlation of the pattern and its frequency on the clinical practice.

Concerning the type of information that should be included in the HEp-2 IFA report, 76\% (316) of the participants indicated the identification of the pattern and $63 \%$ (261) the final titer. It should be emphasized that the dilution of 1:80 is used for SARD screening, but this screening dilution results in $13.3 \%$ positivity in healthy individuals, a fact that the physician must be aware of [21]. Healthy individuals tend to present lower HEp-2 IFA titers, due to the lower serum concentration of natural autoantibodies [12, 21]. Still on the aspects that the rheumatologist considers important in the HEp-2 IFA report, 35\% (144) referred that the history of previous patterns is an important information in the report. SARD are associated with a varied range of autoantibodies, which may fluctuate over time depending on the period of the disease in which the individual is tested [22-25]. Between periods of disease activity and remission, there may be a predominance of one antibody over the other, thus changing the titer and the pattern found [22-26]. Therefore, recording the history of patterns may be relevant for this monitoring. In addition, occasional changes in the pattern may herald a transformation in the clinical scenario. The typical example is a person with ill-defined symptoms that presents the dense fine nuclear pattern (AC-2) for years and comes to the clinical visit bringing a HEp-2 IFA report with the homogeneous nuclear pattern (AC-1). This change in the HEp-2 IFA indicates the appearance of novel autoantibodies that may shed light into the clinical investigation of such a patient. The standardization of the information in the report and the way in which it is presented to the attending physician facilitates the monitoring of the data provided by the screening exam over time and allows a temporal and comprehensive analysis of the patient's condition. 


\section{Conclusion}

The Brazilian Consensus on HEp-2 IFA has been used by the Brazilian community of rheumatologists for two decades and has played an important role in the clinical practice. The data presented here indicate that the guidelines regarding standardization contribute to the uniformity in the presentation of results and in the scope of clinical interpretation.

However, as usually occurs in voluntary response sample studies, responders are differentiated in terms of motivation on the subject of the research. In addition, the sampling represents one fifth of SBR members. These limitations should be taken into consideration and the findings and conclusions should not be freely generalized.

Brazilian rheumatologists are knowledgeable about the BCA literature and most evaluate positively the content available, considering that the recommendations help in clinical practice. Experts also recognize the patterns most commonly associated with rheumatic autoimmune diseases and have used BCA recommendations to interpret the related laboratory findings.

On the other hand, the study pointed out that there is an opportunity to expand the knowledge of rheumatologists on the content of $\mathrm{BCA}$ by means of continuous education, contributing to the update and dissemination of BCA concepts and nomenclature. In parallel, it is equally important to communicate the harmonization of international recommendations to those of the $\mathrm{BCA}$. These initiatives should allow rheumatologists to take the best of the HEp-2 IFA test, contributing to an accurate diagnosis, optimal therapy and greater chances of treatment success.

\section{Abbreviations \\ AC: Anti-cell; ANA: Antinuclear antibody; BCA: Brazilian consensus for detection of autoantibodies; HEp-2: Human epithelial type 2 cells; ICAP: International consensus on ANA patterns; IFA: Indirect immunofluorescent Assay; SARD: Systemic autoimmune rheumatic diseases; SBR: Brazilian rheumatology society; SLE: Systemic lupus erythematosus}

\section{Acknowledgements \\ Sociedade Brasileira de Reumatologia (SBR) (in English, Brazilian \\ Rheumatology Society) and the SBR's Laboratory Commission.}

\section{Authors' contributions \\ WMC, LEA, PLCF are design of the questionnaire. ICMF and LARS applied the questionnaire with the support of the SBR laboratory commission. ICMF and LARS elaborate of the first paper draft. WMC, LEA, PLCF are review of the manuscript. All authors read and approved the final manuscript.}

\section{Funding}

There is no funding to be declared, except for the support of the Sociedade Brasileira de Reumatologia / Comissão de Laboratórios in providing support for the development of the study and a scientific initiation scholarship provided by CNPq.

\section{Availability of data and materials}

Not applicable. This manuscript refers to the proceedings of a meeting with a panel of experts and, therefore, there is available research data or materials.

\section{Declarations}

Ethics approval and consent to participate

Not applicable. This manuscript refers to the application of questionnaires and was approved by the Ethics and Research Committee from Pontifical Catholic University of Goiás, report number 2872574.

\section{Consent for publication}

All authors comply with the content of the manuscript.

\section{Competing interests}

The authors of the manuscript declare that they have no competing interests.

\section{Author details}

${ }^{1}$ Pontifícia Universidade Católica de Goiás (PUC Goiás), Escola de Ciências Médicas, Farmacêuticas e Biomédicas, Avenida Universitária 1.440, Setor Universitário, Goiânia, GO, Brazil. 'Disciplina de Reumatologia, Escola Paulista de Medicina, Universidade Federal de São Paulo (UNIFESP), Divisão de Imunologia, Fleury Medicina e Saúde, São Paulo, SP, Brazil.

Received: 16 March 2021 Accepted: 20 May 2021

Published online: 09 June 2021

\section{References}

1. Tan EM. Antinuclear antibodies: diagnostic markers for autoimmune diseases and probes for cell biology. Adv Immunol. 1989;44:93-151. https:// doi.org/10.1016/S0065-2776(08)60641-0.

2. Dellavance $A$, Júnior $A G$, Cintra $A F$, Ximenes $A C$, Nuccitelli $B$, Mühlen $C A$, et al. I consenso nacional para padronização dos laudos de FAN HEp-2 the first Brazilian consensus for standardization of ANA in HEp-2 Cells. J Bras Patol Med Lab. 2002;38(3):201-16.

3. Dellavance A, Junior AG, Cintra AFU, Ximenes AC, Nuccitelli B, Taliberti BH. II Brazilian consensus on antinuclear factor in HEp-2 cells $\left(^{*}\right)$ II Brazilian consensus on antinuclear antibodies in HEp-2 cells nucleolus, cytoplasm and mitotic apparatus, as wel as its clinical associations. Rev Bras Reumatol. 2003;43(3):129-40. https://doi.org/10.1590/S0482-50042003000300002.

4. Francescantonio PLC, Andrade LEC, de Melo Cruvinel, W, Nuccitelli B, Taliberti BH, et al. III Consenso Brasileiro para Pesquisa de Autoanticorpos em Células HEp-2 : perspectiva histórica, controle de qualidade e associações clínicas. Jornal Brasileiro de Patologia Clínica Vol. 2009;45:18599.

5. Francescantonio PLC, de Melo Cruvinel, W, Dellavance A, Andrade LEC, Taliberti BH, von Mühlen CA, et al. IV Consenso Brasileiro para pesquisa de autoanticorpos em células HEp-2. Rev Bras Reumatol. 2014;54(1):44-50. https://doi.org/10.1016/j.rbr.2013.10.001.

6. de Melo Cruvinel, W, Andrade LEC, von Mühlen CA, Dellavance A, Ximenes AC, Bichara $C D$, et al. $\vee$ Brazilian consensus guidelines for detection of anticell autoantibodies on HEp-2 cells. Adv Rheumatol. 2019;59(1):28.

7. Chan EKL, Damoiseaux J, Carballo OG, Conrad K, de Melo Cruvinel, W, Francescantonio PLC, et al. Report of the first international consensus on standardized nomenclature of antinuclear antibody HEp-2 cell patterns 2014-2015. Front Immunol. 2015;6. https://doi.org/10.3389/fimmu.2015. 00412.

8. Chan EKL, Damoiseaux J, de Melo Cruvinel, W, Carballo OG, Conrad K, Francescantonio PLC, et al. Report on the second international consensus on ANA pattern (ICAP) workshop in Dresden 2015. Lupus. 2016;25(8):797804. https://doi.org/10.1177/0961203316640920.

9. Andrade LEC, Klotz W, Herold M, Conrad K, Rönnelid J, Fritzler MJ, et al. International consensus on antinuclear antibody patterns: definition of the AC-29 pattern associated with antibodies to DNA topoisomerase i. Clin Chem Lab Med. 2018;56(10):1783-8. https://doi.org/10.1515/cclm-2018-0188.

10. Damoiseaux J, von Mühlen CA, Garcia-De La Torre I, Carballo OG, de Melo Cruvinel W, PLC F, et al. International consensus on ANA patterns (ICAP): the bumpy road towards a consensus on reporting ANA results. Autoimmun Highlights. 2016;7(1):1-8. https://doi.org/10.1007/s13317-016-0075-0.

11. Herold M, Klotz W, Andrade LEC, Conrad K, de Melo Cruvinel, W, Damoiseaux J, et al. International consensus on antinuclear antibody patterns: defining negative results and reporting unidentified patterns. Clin Chem Lab Med. 2018:56(10):1799-802. https://doi.org/10.1515/cclm-20180052. 
12. Damoiseaux J, Andrade LEC, Carballo OG, Conrad K, Francescantonio PLC, Fritzler MJ, et al. Clinical relevance of HEp-2 indirect immunofluorescent patterns: the international consensus on ANA patterns (ICAP) perspective. Ann Rheum Dis. 2019;78(7):879-89. https://doi.org/10.1136/annrheumdis-2 018-214436.

13. Tan EM, Feltkamp TEW, Smolen JS, Butcher B, Dawkins R, Fritzler MJ, et al. Range of antinuclear antibodies in "healthy" individuals. Arthritis Rheum. 1997 Sep;40(9):1601-11. https://doi.org/10.1002/art.1780400909.

14. Satoh M, Chan EKL, Ho LA, Rose KM, Parks CG, Cohn RD, et al. Prevalence and sociodemographic correlates of antinuclear antibodies in the United States. Arthritis Rheum. 2012;64(7):2319-27. https://doi.org/10.1002/art.343 80.

15. Agustinelli RA, Rodrigues SH, Mariz HA, Prado MS, Andrade LEC. Distinctive features of positive anti-cell antibody tests (indirect immunofluorescence on HEp-2 cells) in patients with non-autoimmune diseases. Lupus. 2019;28:62934.

16. Dellavance A, Andrade LEC. Detection of autoantibodies by indirect immunofluorescence Cytochemistry on Hep-2 cells. Methods Mol Biol. 2019; 1901:19-46.

17. Satoh M, Vázquez-Del Mercado M, Chan EKL. Clinical interpretation of antinuclear antibody tests in systemic rheumatic diseases. Mod Rheumatol. 2009:19(3):219-28. https://doi.org/10.3109/s10165-009-0155-3.

18. Kavanaugh A, Tomar R, Reveille J, Solomon DH, Homburger HA. Guidelines for clinical use of the antinuclear antibody test and tests for specific autoantibodies to nuclear antigens. Arch Pathol Lab Med. 2000;124(1):71-81. https://doi.org/10.5858/2000-124-0071-GFCUOT.

19. Petri M, Orbai AM, Alarcõn GS, Gordon C, Merrill JT, Fortin PR, et al. Derivation and validation of the systemic lupus international collaborating clinics classification criteria for systemic lupus erythematosus. Arthritis Rheum. 2012;64(8):2677-86. https://doi.org/10.1002/art.34473.

20. Alessandra D, Coelho ALE. Como interpretar e valorizar adequadamente 0 teste de anticorpos antinúcleo. J Bras Patol Med Lab. 2007;43(3):157-68.

21. Mariz HA, Sato El, Barbosa SH, Rodrigues SH, Dellavance A, Andrade LEC Pattern on the antinuclear antibody-HEp-2 test is a critical parameter for discriminating antinuclear antibody-positive healthy individuals and patients with autoimmune rheumatic diseases. Arthritis Rheum. 2011;63(1):191-200. https://doi.org/10.1002/art.30084

22. Hargraves MM. Discovery of the LE cell and its morphology. Mayo Clin Proc. 1969:44(9):579-99.

23. Fritzler MJ. Antinuclear antibodies in the investigation of rheumatic diseases. Bull Rheum Dis. 1985;35(6):1-10 PMID: 3879803.

24. von Mühlen CA, Tan EJM. Autoantibody in the diagnosis of systemic rheumatic diseases. Semin Arthritis Rheum. 1995;24(5):323-58. https://doi. org/10.1016/S0049-0172(95)80004-2.

25. Evans J. Antinuclear antibody testing in systemic autoimmune disease. Clin Chest Med. 1998;19(4):613-25. https://doi.org/10.1016/S0272-5231(05)701 06-4.

26. Prado MS, Dellavance A, Rodrigues SH, Marvulle V, Andrade LEC. Changes in the result of antinuclear antibody immunofluorescence assay on HEp-2 cells reflect disease activity status in systemic lupus erythematosus. Clin Chem Lab Med. 2020;58(8):1271-81.

\section{Publisher's Note}

Springer Nature remains neutral with regard to jurisdictional claims in published maps and institutional affiliations.

Ready to submit your research? Choose BMC and benefit from:

- fast, convenient online submission

- thorough peer review by experienced researchers in your field

- rapid publication on acceptance

- support for research data, including large and complex data types

- gold Open Access which fosters wider collaboration and increased citations

- maximum visibility for your research: over $100 \mathrm{M}$ website views per year

At $\mathrm{BMC}$, research is always in progress.

Learn more biomedcentral.com/submissions 